\title{
Valve-in-valve transcatheter aortic valve replacement: the challenge of the next future
}

\author{
Gianmarco Annibali, Innocenzo Scrocca, Giuseppe Musumeci \\ Cardiology Division, Azienda Ospedaliera Ordine Mauriziano Umberto I, Turin 10128, Italy. \\ Correspondence to: Dr. Giuseppe Musumeci, Cardiology Division, Azienda Ospedaliera Ordine Mauriziano Umberto I, Largo \\ Filippo Turati, 62, Turin 10128, Italy. E-mail: giuseppe.musumeci@gmail.com
}

How to cite this article: Annibali G, Scrocca I, Musumeci G. Valve-in-valve transcatheter aortic valve replacement: the challenge of the next future. Mini-invasive Surg 2022;6:12. https://dx.doi.org/10.20517/2574-1225.2021.101

Received: 27 Aug 2021 First Decision: 13 Dec 2021 Revised: 14 Jan 2022 Accepted: 27 Jan 2022 Published: 24 Feb 2022

Academic Editor: Andrea Scotti Copy Editor: Yue-Yue Zhang Production Editor: Yue-Yue Zhang

\begin{abstract}
In recent years, an increasing number of bioprostheses have been implanted, and in the near future more and more patients will be candidates for reoperation due to structural deterioration of the valve. Valve-in-valve transcatheter aortic valve replacement (ViV TAVR) has become a safe and effective alternative to surgery and is currently approved for higher-risk, inoperable patients. From the most recent studies, early mortality has decreased and improvements in symptoms and quality of life of treated patients have been documented. ViV TAVR is a complex procedure that can present many pitfalls and therefore must be performed in high volume centers and with experienced staff because the risk of peri- and post-procedural complications is much higher than TAVR on native valve. In this review, we analyze the main procedural issues reported in the literature during ViV TAVR procedures: elevated postprocedural gradients, coronary obstruction and thrombosis of the leaflets of the bioprosthesis. Because of the opening of TAVR to younger and younger patients, thus with a longer life expectancy than the durability of the bioprosthesis, the next challenge will be the management of the lifetime strategy of patients with aortic stenosis, as the first type of intervention will influence all future therapeutic choices of our patient.
\end{abstract}

Keywords: Transcatheter aortic valve replacement, valve-in-valve, structural valve deterioration, bioprosthetic valve failure

\section{INTRODUCTION}

In the last decade, transcatheter aortic valve replacement (TAVR) has dramatically changed the 
management of symptomatic severe aortic stenosis. TAVR has now been approved in patients with severe symptomatic aortic stenosis across all surgical risk profiles and for patients with failed bioprosthetic valves (BVs). Valve-in-valve (ViV) TAVR has emerged as an alternative to surgical aortic valve replacement (SAVR) in patients at high operative risk, now accounting for approximately $5 \%$ of all TAVR procedures performed in the United States ${ }^{[1]}$. BVs are increasingly being used for young patients, at the expense of mechanical valves, and this will result in a major increase in reinterventions in the next future. Data currently available from large registries are encouraging in terms of safety and long-term survival with oneyear survival rates exceeding $80 \%^{[2-4]}$.

To identify a dysfunctional valve, in 2017, a consensus document from the European Society of Interventional Cardiology (EAPCI), the European Society of Cardio-Thoracic Surgery, and the European Society of Cardiology defined structural valve deterioration as: (1) mean gradient $\geq 40 \mathrm{mmHg}$ and/or $\geq 20$ $\mathrm{mmHg}$ change from baseline (before discharge or within 30 days of valve implantation); and/or (2) severe new or worsening intra-prosthetic aortic regurgitation ${ }^{[5]}$. More recently, in the Valve Academic Research Consortium (VARC)-3, four main categories of aortic bioprosthetic dysfunctions have been defined, based on the main etiopathogenetic mechanisms: structural valve deterioration (SVD), non-structural valve deterioration (NSVD) (e.g., paravalvular regurgitation and prosthesis-patient mismatch), thrombosis and endocarditis ${ }^{[6]}$.

ViV TAVR is more complex than native valve TAVR and should ideally be performed by experienced teams after a multidisciplinary decision in the heart team according to the latest guidelines ${ }^{[7,8]}$. Therefore, a standardized approach and a meticulous pre-procedural planning are the keys to success. The purpose of this review is to give a contemporary overview regarding the current and future challenges of this procedure.

\section{CHOOSING THE BEST TREATMENT FOR DEGENERATED BIOPROSTHESIS}

Although, to date, there are no data from randomized trials regarding the best treatment of SVD, data from meta-analyses have demonstrated a lower incidence of postoperative complications and 30-day mortality with similar one-year and midterm mortality rates for TAVR ViV compared with redo SAVR, despite increased rates of major bleeding, myocardial infarction and severe prosthesis-patient mismatch ${ }^{[9-11]}$.

ViV TAVR is currently the treatment of choice for patients with degenerated surgical BVs considered to be at high or extreme risk for a redo SAVR. In contrast, redo SAVR remains the first choice in patients at intermediate or low surgical risk unless there are unfavorable anatomies (e.g., calcified aortic root or hostile chest). Younger age ( $<75$ years old), thus greater life expectancy, and unfavorable coronary anatomy due to high risk of coronary artery obstruction should be considered predisposing factors toward redo SAVR given the current lack of long-term data regarding ViV TAVR. Other features in favor of redo SAVR are the presence of a severe paravalvular leak or small BVs with severe prosthesis-patient mismatch in which percutaneous closure or bioprosthesis fracture are not feasible $\mathrm{e}^{[12]}$.

\section{BIOPROSTHETIC VALVE CHARACTERISTICS}

Obtaining information about the type of surgery performed and the characteristics of the implanted valve are the first fundamental steps in preparing for the procedure. There are two main groups of bioprosthetic surgical valves: stented and stentless surgical devices ${ }^{[13,14]}$. Stentless valves, representing approximately $20 \%$ of patients with $\mathrm{ViV}$, most frequently present with regurgitation as a modality of degeneration, with lower postprocedural gradients than those observed with stented valves but with higher rates of periprocedural complications as initial device malposition, second transcatheter device, coronary obstruction and 
paravalvular leak, but no difference in 30-day and 1-year outcome ${ }^{[7]}$. Stented valves, especially those with externally mounted leaflets (e.g., Mitroflow, Livanova PLC/Sorin Group, Saluggia, Italy), have frequently been used in the past, mainly in small anatomies, because they guarantee a lower final gradient, but these are the valves at the highest risk for coronary obstruction in ViV procedures ${ }^{[15,16]}$.

The type of transcatheter heart valve (THV) must also be carefully selected. There are supra-annular valves (i.e., functional leaflets placed over the aortic annulus), such as the CoreValve/Evolut (Medtronic, Minneapolis, Minnesota, USA) and the ACURATE (Boston Scientific, Marlborough, MA, USA), whereas others are intra-annular, such as the SAPIEN (Edwards Lifesciences, Irvine, California, USA) and the Portico (Abbott, Lake Bluff, Illinois, USA). There are no randomized comparison studies between TAVR ViV and SAVR or between different transcatheter devices in ViV procedures. From two propensitymatched comparisons between transcatheter valves, the CoreValve family showed greater effective orifice area (EOA), lower mean gradients, lower incidence of moderate-to-severe aortic regurgitation and lower mortality compared with the Portico, whereas a comparison between SAPIEN XT and SAPIEN 3 patients documented lower 30-day mortality in the latter. There were no differences in elevated postprocedural gradients between devices, and SAPIEN 3 patients, because of the different valve profile, were more likely to undergo pacemaker implantation after ViV TAVR (6\% vs. $2.5 \%, P=0.07)^{[17,18]}$.

Computed tomography scan (CT) remains, in the presence or even more in the absence of data regarding the procedure performed or the implanted prosthesis, a fundamental tool for planning a ViV TAVR. Thanks to the CT study, it is therefore possible to have precious information regarding the type of prosthesis, the correct size of the valve and the confirmation of the true internal lumen (ID), which is the true reference measurement for our THV. The ID corresponds to the internal diameter in the case of a valve with externally mounted leaflets, while, in the case of internally mounted leaflets, the internal diameter of the prosthesis will be reduced ${ }^{[19]}$.

Finally, regarding the correct study of the bioprostheses, the "Valve-in-Valve" app developed in collaboration between the technology company UBQO and Dr. Vinayak Bapat is certainly one of the musthave tools for optimal planning of the ViV TAVR procedure ${ }^{[20]}$.

\section{CORONARY OBSTRUCTION}

Compared to TAVR on native valve, ViV TAVR has a higher risk of coronary occlusion ( $0.1 \%$ vs. $3.1 \%)$. Although rare, this complication is one of the most worrisome events and is associated with a higher 30-day mortality compared to an uneventful procedure $(48.6 \% v s .3 .7 \%)^{[14]}$. Obstruction of the left coronary artery is more frequent $(72 \%)$ than obstruction of both ostia $(20 \%)$ or the right coronary artery alone $(8 \%)$. The primary mechanism underlying this event is the displacement of the surgical valve leaflets toward the coronary ostia after valve implantation (58\%), but it can also occur after initial valvuloplasty (3\%), after post-dilatation (3\%), within the first $24 \mathrm{~h}$ after TAVR (22\%), or even afterward (14\%). The obstruction may be partial (57\%) or complete (43\%); the patient presents severely hypotensive (58\%) and with ischemic ECG changes. Percutaneous coronary intervention (PCI) was attempted in $77.8 \%$ of patients, with only $64.3 \%$ successful. Mortality was $22 \%$ in successful PCI and 50\% when patient was referred for emergency coronary artery bypass grafting. Eighty percent of patients with unsuccessful PCI died. In $36 \%$ of cases, coronary obstruction had delayed onset and most of these complications (77\%) occurred in patients with selfexpanding devices because of their ability to continue to expand after the procedure. The incidence of coronary obstruction in TAVR from failed surgical prostheses is much higher in externally mounted valves (6.4\%) and stentless valves (3.7\%), compared with those with internally mounted leaflets (0.7\%). Stentless and stented valves with externally mounted leaflets, such as Mitroflow (Livanova PLC/Sorin Group, 
Saluggia, Italy) and Trifecta (Abbott), were the only factors independently associated with coronary obstruction $^{[16]}$.

As mentioned above, a rare event is then delayed coronary obstruction (DCO), defined as an obstruction that occurs after the patient leaves the operating room after TAVR. It is more common in TAVR ViV after self-expanding valve implantation. DCO was found in the first seven days after the procedure (63\%), in $47 \%$ of cases within $24 \mathrm{~h}$, but also after 60 days (37\%). Presentation with cardiac arrest was the most frequent (32\%). Mechanisms underlying early DCO, the one associated with higher mortality, include continuous THV expansion, coronary dissection and aortic root hematoma. Mechanisms of late obstruction include endothelization of native or surgical bioprosthetic leaflets or thrombus embolization that may occur in the TAVR valve or sinus of Valsalva ${ }^{[21]}$.

Other patients at high risk for coronary obstruction are those with small anatomies, especially narrow sinuses of Valsalva, narrow sinotubular junction (STJ) and low coronary ostium. These patients have often received a small surgical valve, which therefore increases the potential risk of coronary obstruction ${ }^{[14]}$. According to data from the Valve-in-Valve International Data (VIVID) registry, 28\% of ViV TAVR were labeled as $21 \mathrm{~mm}$ valves and, in the PARTNER surgical arm, approximately one-third of patients had undergone cardiac surgery with a small valve $\mathrm{e}^{[22,23]}$.

As recently demonstrated by Ochiai et al. ${ }^{[24]}$, pre-TAVR CT scan can predict the risk of coronary obstruction due to sinus sequestration in patients undergoing redo TAVR with low STJ height. After a postTAVR CT analysis, they documented a statistically significant difference in terms of coronary obstruction due to sinus sequestration between the two groups (Evolut R/Evolut PRO group $45.5 \%$ vs. Sapien 3 group $2.0 \%, P<0.001)$ and the inability to perform a preventive leaflet laceration procedure because of the overlaps between the first THV commissural posts and the coronary ostium in a significant proportion of patients. Thus, they concluded that a THV with low commissure height that was designed to achieve commissure-to-commissure alignment with the native aortic valves may be preferable to avoid the risk of coronary obstruction due to sinus sequestration and allow for a preventive leaflet laceration procedure in future redo $\mathrm{TAVR}^{[24]}$.

As identified by the Vancouver group, another key piece of information given by the pre-TAVR CT study is the virtual distance between the THV and the coronary ostium, which has been shown to be a reliable predictor of coronary obstruction. A virtual ring of the same diameter as the planned TAVR is inserted in the center of the degenerated bioprosthesis, positioned at the height of the coronary ostium with a coplanar alignment to more accurately reflect the position of the future prosthesis. This measure was defined as virtual transcatheter valve-to-coronary distance (VTC). A VTC below $4 \mathrm{~mm}$ is a very accurate cut-off, with high sensitivity and specificity $(P<0.001)$. There were no differences in ostium height between patients with and without coronary obstruction ${ }^{[25]}$. Distances of VTC and valve-to-STJ (VTSTJ) $<3 \mathrm{~mm}$ would be considered at high risk of coronary obstruction as demonstrated by Dvir et al. ${ }^{[26]}$.

To prevent this terrible complication, one of the most used techniques consists in the placement of a guiding catheter and a coronary guidewire in the coronary artery at risk with a coronary balloon or an undeployed stent ready to be used in case of coronary obstruction (chimney technique ${ }^{[27,28]}$. Urgent stenting of the left main was necessary in approximately $20 \%$ of patients who underwent coronary protection ${ }^{[16]}$. Unfortunately, even this technique may be associated with several complications such as inability to withdraw the stent, mechanical deformation of the stent caused by the bioprosthesis or inability to re-access to the coronary arteries in the future. In addition, there are no data regarding the long-term patency of these 
stents $^{[13]}$.

Another technique developed to prevent coronary obstruction is the Bioprosthetic Aortic Scallop Intentional Laceration to prevent Iatrogenic Coronary Artery obstruction (BASILICA) procedure ${ }^{[29]}$. Since the first one in 2017, dozens of procedures have been performed worldwide with satisfactory results. The valve leaflets are lacerated via an electrified guidewire, thereby facilitating blood flow to the coronary artery. Pending data regarding the BASILICA procedure in TAVR ViV, those currently available in the literature demonstrate excellent success rates and low mortality rates in high-risk patients for coronary obstruction undergoing TAVR over native valve $\mathrm{e}^{[30-32]}$.

After THV implantation, the leaflets of the degenerated surgical prosthesis will be tilted up, thus creating a covered cylindrical stent through which it will be impossible to pass a coronary catheter. The height of this barrier, previously called neoskirt ${ }^{[33-36]}$, will be determined by the length of the degenerated surgical prosthesis leaflets. Several factors must be considered when assessing the risk of coronary artery re-access: the size of the STJ, the location of the coronary ostia in relation to the neoskirt and the type of the THV ${ }^{[12]}$.

A coronary artery obstruction risk classification was created in 2019 from the VIVID registry. Through an anatomical classification of the aortic root and valve leaflet location to determine the possible need for the BASILICA procedure, three types of patients were identified: Type I with aortic valve leaflets below the coronary ostium; Type II with leaflets above the ostium in the presence of wide (IIA) or effaced sinuses (IIb); and Type III leaflets above or very close to the STJ with wide STJ/sinuses (IIIA), with effaced sinuses (IIIB), and with narrow STJ (IIIC). According to this algorithm, the BASILICA procedure should be considered in case of a VTC $<4 \mathrm{~mm}$ as in Types IIB, IIIB, and IIIC ${ }^{[37]}$.

Regarding TAVR-in-TAVR procedures, Tarantini et al. ${ }^{[33]}$ proposed an algorithm based on the anatomy of the aortic root and its interaction with the different THVs to predict the risk of acute coronary occlusion and feasibility of future coronary access after TAVR-in-TAVR. Through a combined CT and coronary angiography analysis, they identified the risk plane (RP) as the level below which the passage of a coronary catheter will be impossible after the second THV and identified different types of scenarios based on the patient's anatomy and the first THV implanted. Coronary artery re-access will be possible in Type 1, with coronary ostia below the RP, and Type $2 \mathrm{a}$, with coronary ostia below the RP but with the valve-to-aorta distance $(V T A)>2 \mathrm{~mm}$, particularly if the THV type used for ViV TAVR has an open-cell design ${ }^{[38]}$. Instead, Type $2 \mathrm{~b}$, with coronary ostia below the RP and VTA $<2 \mathrm{~mm}$, is associated with a high risk of coronary obstruction $^{[33]}$. The use of a THV with a low frame is certainly an advantage over supra-annular THVs with higher frames and higher asymmetric commissures. During implantation, proper commissure alignment, possible with some partially orientable devices as Evolut (Medtronic, Minneapolis, MN, USA) and ACURATE (Boston Scientific, Marlborough, MA, USA), with the surgical bioprosthesis or the first THV will be critical because misalignment could make re-access to the coronary ostia impossible ${ }^{[12,39]}$. All factors related to coronary obstruction are resumed in Figure 1.

\section{PROSTHESIS-PATIENT MISMATCH AFTER VIV TAVR}

Prosthesis-patient mismatch (PPM) occurs when the EOA of a normally functioning prosthesis is too small in relation to the patient's body size, causing abnormally high postoperative gradients. Severe PPM is defined as an indexed effective orifice area (iEOA) $<0.65 \mathrm{~cm}^{2} / \mathrm{m}^{2}$ following aortic valve replacement ${ }^{[40]}$. The PPM is relatively frequent following SAVR in patients with small anatomies and becomes a problem to consider during the planning process of patients with degenerated small aortic bioprosthesis. Female sex is a strong clinical predictor of PPM after SAVR. In addition, older age, hypertension, diabetes, renal failure, 


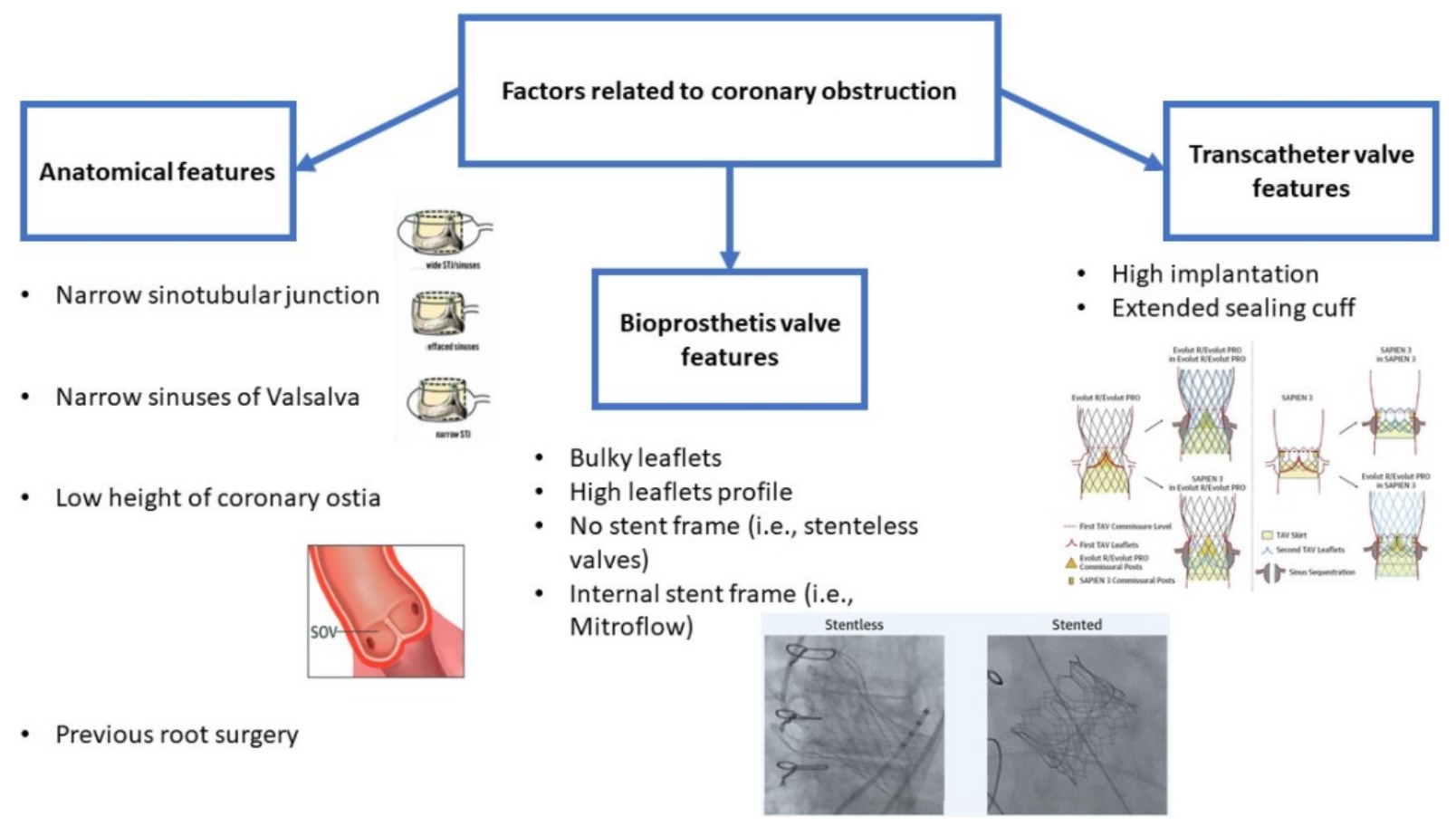

Figure 1. Factors related to coronary obstruction.

and a higher surgical risk score predict the likelihood of PPM, suggesting that PPM may be a surrogate marker for adverse outcomes ${ }^{[22]}$. Surgical $19 \mathrm{~mm}$ biological valves have a "physiological" mean gradient of approximately $25 \mathrm{mmHg}$ if the leaflets of the valve are sutured inside the posts of the stent (e.g., CarpentierEdwards Pericardial) and around $10 \mathrm{mmHg}$ if the leaflets are sutured outside the stent frame (e.g., Mitroflow) $)^{[41]}$.

A TAVR ViV is associated with a higher risk of high residual severe gradients and one-year mortality. In the STS/ACC TVT and VIVID registries, more than $30 \%$ of ViV procedures were associated with severe residual gradients after surgery ${ }^{[2,42]}$. ViV TAVR was associated with hemodynamic deterioration with gradient increase of more than $10 \mathrm{mmHg}$ between discharge and 30-day follow-up in the TVT registry ${ }^{[33]}$. Patients at even greater risk are those who have undergone SAVR, with PPM, and then arrive with SVD ${ }^{[2,44]}$. Severe PPM before the ViV procedure was associated with higher 30-day and 1-year mortality and a postprocedure gradient greater than $20 \mathrm{mmHg}^{[45]}$. To try to reduce the risk of having a high post-procedure gradient, some measures can be taken, such as the choice of a supra-annular valve and a high THV implant. Self-expandable (SE) valves, compared with balloon-expandable (BE) valves, are associated with lower post$\mathrm{ViV}$ gradients, especially in severe preexisting $\mathrm{PPM}^{[46]}$. In TAVR, deep implantation of a SE valve is a stronger predictor of PPM than age, annulus size, left ventricular outflow tract, and valve size ${ }^{[47]}$. The recommended cut-offs for high positioning for CoreValve/Evolut and SAPIEN 3 are $5 \mathrm{~mm}$ and 20\%, respectively ${ }^{[48]}$. However, the optimal height and deployment dimensions for ViV prostheses are still unclear. In vitro testing, lower gradients, and larger orifice areas are achieved with taller implants that provide more freedom to the leaflets ${ }^{[49]}$. Higher implantation, however, is associated with an increased risk of residual regurgitation and valve embolization, which varies between prosthesis types ${ }^{[5,51]}$. Seiffert et al. ${ }^{[18]}$ and Dvir et al..$^{[52]}$ recommended an optimal depth of $3 \mathrm{~mm}$ for the Medtronic SE valve and $80 \%$ aortic/20\% ventricular for the Edwards valve. Increased THV size is not always associated with increased EOA. In vitro, a higher EOA was observed for the Trifecta and Epic Supra valves but a lower EOA for the Mitroflow. 
An increased risk of embolization has been documented by placing a larger prosthesis in an Epic Supra ${ }^{[51]}$. In addition, SVD is more rapid if the THV is not fully expanded ${ }^{[53]}$.

Furthermore, the VIVID registry has developed a TAVR ViV calculator that can calculate the expected PPM at the end of the procedure, available at http://valveinvalve.org ${ }^{[14]}$.

All of the factors that jointly result in a high post-procedural gradient are summarized in Table 1.

\section{BIOPROSTHETIC VALVE FRACTURE}

In addition to the higher THV implantation techniques, another technique that can be used in the case of high post-procedural gradient is the bioprosthetic valve fracture (BVF). BVF has been proposed as a technique to increase the true ID of the THV to allow either a larger THV or a better expanded THV to be implanted in order to optimize hemodynamic performance ${ }^{[12]}$. However, not all stented valves are prone to fracture. As demonstrated by bench tests, Abbott Trifecta and Medtronic Hancock II valves cannot be fractured $^{[54,55]}$ [Figure 2]. Sutureless and stentless valves are also not eligible for BVF but can be subjected to balloon valve remodeling (BVR) by overexpansion ${ }^{[12]}$. BVF is performed using a high-pressure, noncompliant balloon, such as the Atlas Gold (BARD Peripheral Vascular, Tempe, Arizona, USA) and TRUE balloon (BARD Peripheral Vascular), that is chosen $1 \mathrm{~mm}$ smaller than the size of the prosthesis ${ }^{[56]}$. Using a $60 \mathrm{~mL}$ syringe plus an indeflator assembly connected with a high-pressure three-way stopcock, under rapid ventricular pacing, the syringe is quickly emptied to inflate the balloon, then switched to cranking the indeflator to achieve high-pressure inflation ${ }^{[57]}$.

Although BVF can be performed before or after TAVR ViV, most are performed after TAVR. While BVF prior to TAVR facilitates implantation of a SE valve with less sizing mismatch and confirms successful fracture prior to implantation, it may also cause hemodynamic instability due to severe acute aortic regurgitation and the need for post-dilation to optimize hemodynamics ${ }^{[12]}$. BVF after TAVR ViV, instead, may ensure greater THV expansion and reduce the risk of hemodynamic instability due to acute severe aortic regurgitation after fracture with the risk of possible injury to the prosthesis leaflets e with unknown long-term effect on THV durability ${ }^{[1,58,59]}$. Possible complications of BVF include hemodynamic instability, THV migration, coronary artery obstruction, annular rupture, THV damage, leaflet tearing, accelerated degeneration, and debris displacement ${ }^{[54]}$.

The pros and cons of performing BVF before or after transcatheter valve implantation are resumed in Table 2.

To address the problem of annular fracture, a new surgical bioprosthesis (Inspiris Resilia, Edwards Lifesciences, Irvine, CA) was made with a peculiar zone in its frame which allows expansion via a BVR mechanism. A cobalt-chromium alloy wire makes the valve able to expand more during ViV TAVR with the possibility of being able to implant a larger $\operatorname{TAVR}^{[0]}$. Despite everything, however, some patients may benefit more from a surgical reintervention with annular enlargement or replacement techniques; the main factor to consider being the patient's life expectancy ${ }^{[61]}$.

\section{TAVR-IN-TAVR AND FUTURE PERSPECTIVES IN YOUNG PATIENTS}

With the release of the PARTNER (Placement of AoRtic TraNscathetER Valves) 3 and Evolut Low Risk trials, TAVR procedures will increasingly include younger and low-risk patients, and this could lead to an issue regarding the future management pathway for patients with aortic stenosis ${ }^{[2,63]}$. 
Table 1. Correlates for residual high postprocedural gradients after ViV TAVR. Adapted from Simonato et al. ${ }^{[14]}$

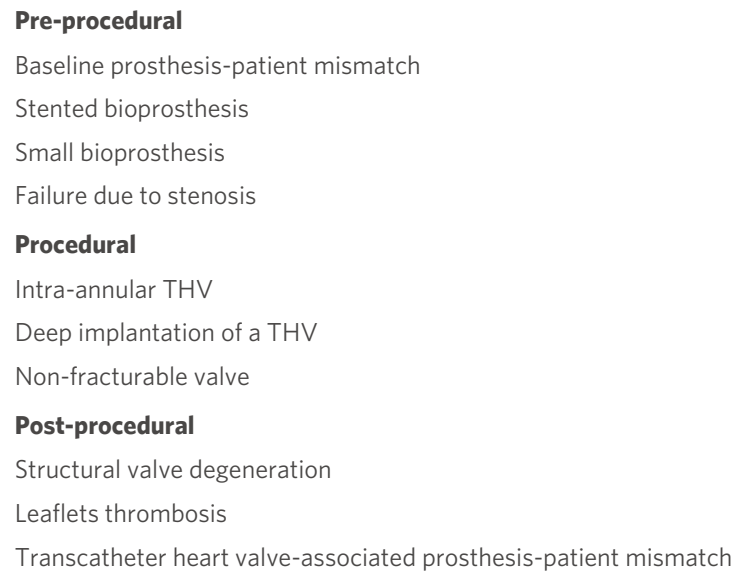

THV: Transcatheter heart valve.

Table 2. Pros and cons of performing BVF before or after ViV TAVR

\begin{tabular}{|c|c|c|}
\hline & Pros & Cons \\
\hline $\begin{array}{l}\text { BVF before ViV } \\
\text { TAVR }\end{array}$ & $\begin{array}{l}\text { Facilitates implantation of a self-expanding valve with less sizing } \\
\text { mismatch } \\
\text { Confirms successful fracture prior to implantation }\end{array}$ & $\begin{array}{l}\text { Hemodynamic instability due to severe acute aortic } \\
\text { regurgitation } \\
\text { - Need for post-dilation to optimize hemodynamics }\end{array}$ \\
\hline $\begin{array}{l}\text { BVF after ViV } \\
\text { TAVR }\end{array}$ & $\begin{array}{l}\text { Greater THV expansion } \\
\text { Reduce the risk of hemodynamic instability due to acute severe } \\
\text { aortic regurgitation }\end{array}$ & $\begin{array}{l}\cdot \text { THV migration } \\
\text { - THV damage or leaflet tearing } \\
\text {. Unknown long-term effect on THV durability }\end{array}$ \\
\hline
\end{tabular}

BVF: Balloon valve fracture; ViV TAVR: valve-in-valve transcatheter aortic valve replacement; THV: transcatheter heart valve.

In the case of a patient with aortic stenosis and long-life expectancy, greater than the durability of BVs, the Heart Team must anticipate the impact of the first intervention on future treatment options.

In fact, in addition to life expectancy, we must keep in mind, at the first intervention, the type of the bioprosthesis we will implant and the anatomy of the aortic root ${ }^{[64]}$.

In patients who are candidates for TAVR, THV with short frame and large open stent frame cells seems to be a better first choice in case of large aortic roots and high coronary ostium, in the case of anatomies that do not prevent the implantation of a future second or third $\mathrm{THV}^{[39,65]}$.

On the contrary, subjects with low coronary ostia and small aortic root could face more risks and procedural difficulties in view of a future TAVR-in-TAVR; therefore, a SAVR with large valves and possibility of aortic root enlargement should be offered, always considering a possible future TAVR-inSAVR and, theoretically, a possible TAVR-in-TAVR-in-SAVR ${ }^{[64]}$.

As the number of TAVR implants increases, surgical TAVR explantations are also on the rise. From currently available data, the clinical effects of explant of chronically implanted TAVR with potential need for aortic repair are not negligible and should be considered in the lifelong management of patient with aortic stenosis ${ }^{[6,67]}$. If the adverse outcomes are confirmed over the next few years, TAVR should not be performed as a first intervention in patients in whom TAVR explantation will be the only possible future reintervention. However, TAVR explant will remain the primary therapy in patients with THV 


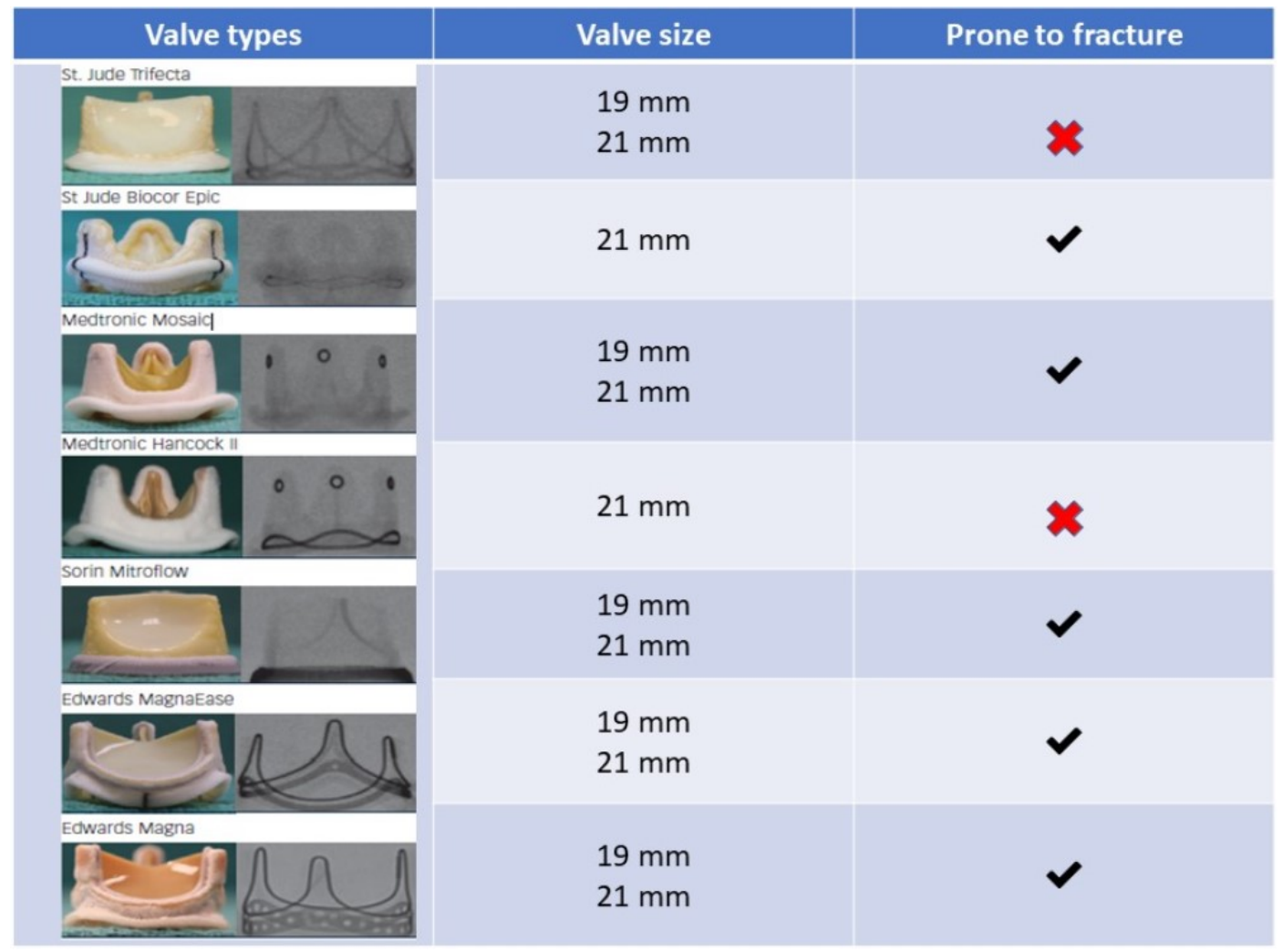

Figure 2. Stented valves prone to fracture.

endocarditis, those with severe paravalvular leak, other heart or aortic diseases, and at high risk of coronary $\operatorname{artery}_{\text {occlusion }}^{[64]}$.

Indeed, while TAVR is associated with almost twice the in-hospital mortality compared with SAVR, TAVRin-TAVR represents a less invasive therapeutic option, with reduced 30-day mortality and lower incidence of major adverse cardiac events ${ }^{[6-70]}$. Unfortunately, this will not be a feasible procedure for all patients; therefore, one must be aware of the future importance of the first treatment decision in the young patient with aortic stenosis ${ }^{[64]}$.

The need to implant a second (or third) TAVR for acute bioprosthesis failure occurs in $1.4 \%-6.7 \%$ of cases (most frequently for acute aortic regurgitation), with satisfactory long-term results similar to those with a single valve $e^{[18,53,56]}$ [Figure 3]. In the case of a larger annulus, the likelihood of a second valve is higher ${ }^{[71]}$. Outcomes of TAVR for treatment of failed THVs, albeit in a small series, appear satisfactory ${ }^{[72]}$. In the absence of data regarding the bioprosthesis, pre-procedure CT planning is critical to assess its internal diameter at the level of leaflets insertion ${ }^{[25]}$.

In the case of TAVR SVD, it is possible to insert a valve of similar size to the one placed in the original procedure. In the case of a BE valve inside a SE valve, we can use the annulus measurements of the original native valve to select the valve size. A BE valve within a SE valve can effectively treat, via a sealing effect, moderate-to-severe paravalvular regurgitation by exploiting the increased radial strength of the $\mathrm{BE}^{[13]}$. 


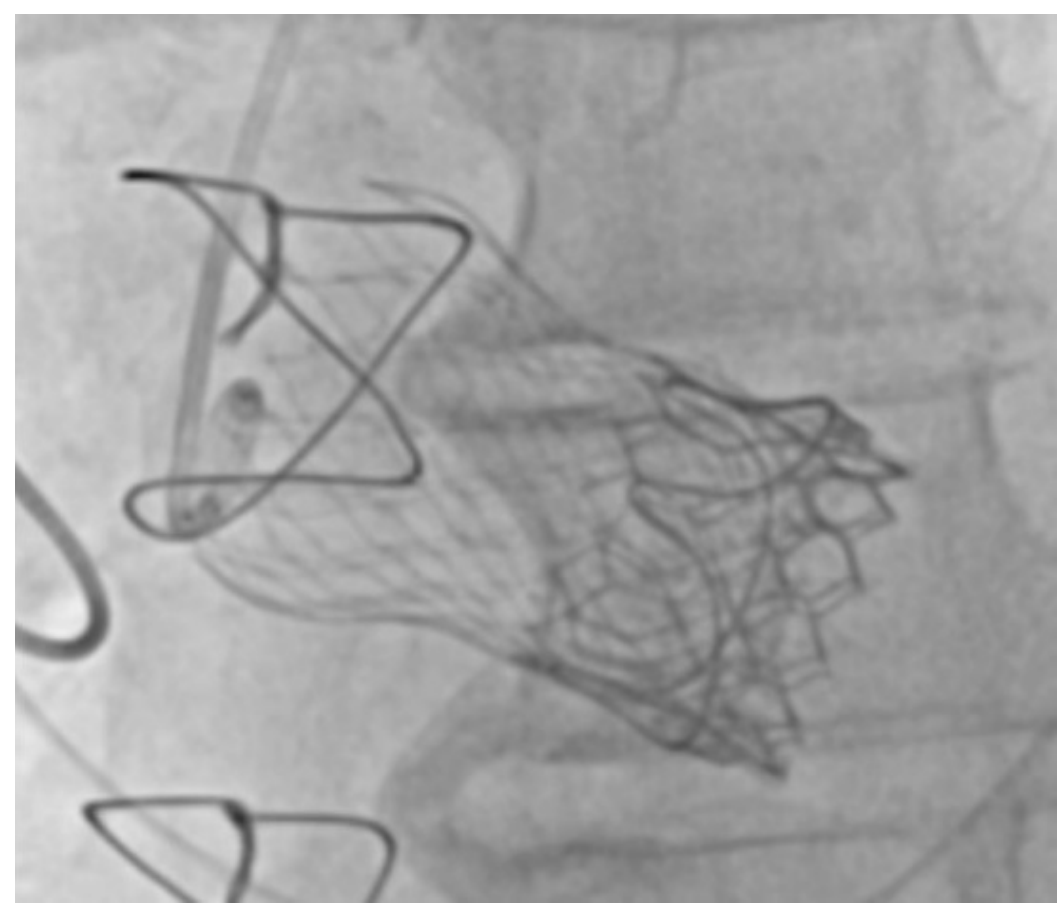

Figure 3. TAVR-in-TAVR after ViV TAVR. A degenerated Carpentier-Edwards Perimount $27 \mathrm{~mm}$ bioprosthesis (Edwards Lifesciences, Irvine, California, USA) treated with a first TAVR CoreValve Evolut R $29 \mathrm{~mm}$ (Medtronic, Minneapolis, Minnesota, USA) and a subsequent Sapien3 Ultra 26 mm (Edwards Lifesciences, Irvine, California, USA), due to damage to CoreValve leaflets after postdilation by incomplete expansion with severe aortic regurgitation.

After TAVR, coronary treatment can be challenging, but it is reported with a good success rate in more than $90 \%$ of cases ${ }^{[59]}$. The risk of coronary artery obstruction should be assessed similarly to that of a surgical BV with particular caution regarding STJ height as mentioned above. Placement of a second TAVR, especially if SE, can make access to the coronary arteries much more difficult, so it is even more important to perform a correct implantation that respects the origin of the coronary ostia and the valve commissures ${ }^{[13,73]}$.

Finally, long-term outcome from the VIVID registry revealed an eight-year survival rate of 38.0\% after ViV TAVR with the main factors related to mortality and reintervention were small true ID, pre-existing severe $P P M$ and $B E$ valve use $\mathrm{e}^{[74]}$.

\section{POST-IMPLANT VALVE THROMBOSIS}

Subclinical leaflet thrombosis is defined as the presence of a reduced leaflet motion associated with hypoattenuating lesions on CT and an increased number of transient ischemic attacks ${ }^{[75]}$. Hypo-attenuated leaflet thickening is an increase in the thickness of the bioprosthetic leaflets with typical meniscal appearance in at least two different multiplanar projections, evidenced on contrast-enhanced CT scan, with still unclear effects on patient outcome and on the long-term valve function ${ }^{[6,77]}$. A semi-quantitative classification has been assumed by describing the percentage of leaflet involvement starting from its basal insertion. Causes of leaflet thickening and reduced leaflet motion include leaflet thrombosis, endocarditis, leaflet deterioration and valve frame expansion issues ${ }^{[6]}$.

Reduction in leaflets motion caused by thrombosis has been noted in both TAVR and SAVR valves ${ }^{[78]}$. Data from the different registries show that reduced leaflet motion is a relatively common event involving $4 \%$ of SAVR patients and $13 \%$ of TAVR patients ${ }^{[75]}$. Thrombosis of the transcatheter-implanted aortic valve rarely 
leads to heart failure because of increased transvalvular gradients $(1 \%-3 \%)^{[79-81]}$.

In recent studies, subclinical leaflets thrombosis has been identified in a quarter of patients on antiplatelet therapy, and there is evidence that oral anticoagulants prevent and can effectively regress leaflets thrombosis with a significant reduction of valve gradient, although subclinical leaflets thrombosis may regress spontaneously ${ }^{[77,82,83]}$. Some observational studies have shown an increase in thromboembolic events in patients with subclinical leaflets thrombosis, but this has not been confirmed in the GALILEO trial and other studies. The PARTNER-3-CT sub-study showed only a slightly higher valvular gradient when there was present subclinical leaflets thrombosis at both 1 and 12 months $^{[84]}$.

ViV TAVR patients need to be considered at high risk of THV leaflets thrombosis for several reasons. In the case of a very low implant, the THV will work with suboptimal hemodynamics with altered flow patterns, creating a milieu for leaflet degeneration and, possibly, for thrombosis. Conversely, in the case of a very high implant, which is requested in ViV procedures inside small surgical valves in order to achieve the lowest possible gradient, there are ex-vivo bench-test data showing produced blood flow in some regions between the two prostheses ${ }^{[75,85]}$. From computational study with flow fields, one of the hypothesized mechanisms underlying this phenomenon is considered to be the geometric confinement of TAVR leaflets by failed bioprostheses, which promotes the slowing of blood flow and promotes leaflet thrombosis ${ }^{[86]}$. Thrombosis events were more commonly described in patients with Mosaic (Medtronic) and Hancock II (Medtronic) compared with other prostheses $(20.3 \%$ vs. $7.2 \%)$ in patients without anticoagulant therapy ${ }^{[83]}$. Among the hypotheses evaluated, it appears that this complication may result from design factors ${ }^{[87]}$. Therefore, a more aggressive anticoagulation regimen after ViV TAVR is recommended, especially in patient with high thrombotic risk and low hemorrhagic risk ${ }^{[7]}$.

Nowadays, there are no robust randomized data on antiplatelet versus anticoagulation after ViV TAVR. Based on recent studies and randomized controlled trials, a viewpoint document, that provides up-to-date therapeutic insights into the peri- and post-TAVI antithrombotic treatment but with no particular recommendations regarding ViV TAVR, was recently released ${ }^{[52]}$. Finally, the optimal antithrombotic regimen after ViV TAVR procedures should be based on the patient's specific anatomical (e.g., higher risk of leaflet thrombosis) and clinical (e.g., atrial fibrillation) characteristics ${ }^{[12]}$.

\section{STROKE RISK IN VIV TAVR}

Stroke is an independent risk factor for increased mortality following TAVR ${ }^{[88]}$. Embolization is the main etiopathogenetic mechanism in the periprocedural period, while late events may be either device related or spontaneous. Despite the substantial decline in stroke rates after TAVR in the most recent trials, it remains one of the most important adverse events ${ }^{[6]}$.

Although degenerated surgical bioprostheses are often calcified and more fragile, no statistically significant difference in stroke rates was identified between ViV TAVR and TAVR on native valve ${ }^{[89]}$. Furthermore, as reported in a recent meta-analysis by Macherey et al.$^{[90]}$, quantitative analysis demonstrated no statistically significant difference in 30-day stroke rates, 30-day mortality, and 1-year mortality among ViV TAVR, TAVR on native valve and redo SAVR ${ }^{[90]}$.

Studies on cerebral embolic protection device (CEPD) have been conducted primarily on TAVR on native valves and have been shown to reduce stroke rates but without reducing procedural complication rates or length of stay. Debris material, thrombus, valve tissue, aortic wall or calcification, captured by a CEPD in ViV TAVR, does not appear to be different from native TAVR procedures ${ }^{[91-93]}$. Therefore, CEPD use should 
be individualized based on operative risk factors (e.g., expected increase in catheter manipulation, multiple repositioning maneuvers, pre- and post-dilatation/BVF, and BASILICA procedure $)^{[12]}$.

\section{CONCLUSION}

ViV TAVR is a safe, effective and well-established procedure supported by increasingly convincing data. The procedure is a viable alternative treatment option for failed surgical bioprosthetic valves, currently approved for patients judged to be at prohibitive risk for surgical redo. It is a complex procedure that can present many pitfalls and therefore must be performed in high volume centers and with experienced personnel because the risk of peri- and post-procedural complications is much higher than TAVR on native valve. Techniques such as BASILICA or surgical prosthesis fracture have reduced the rate of postprocedural complications such as elevated postprocedural gradients, coronary obstruction and leaflet thrombosis while improving the safety and long-term outcomes of the procedure. Because of the opening of TAVR to younger and younger patients, thus with a longer life expectancy than the durability of the bioprosthesis, the next challenge will be the management of the lifetime strategy of patients with aortic stenosis, as the first type of intervention will influence all future therapeutic choices of our patient.

\section{DECLARATIONS}

\section{Authors' contributions}

Performed data analysis, interpretation and manuscript write up: Annibali G

Technical description of operative steps, data acquisition: Annibali G

Review of manuscript: Annibali G, Scrocca I

Review and substantial contributions to conception and design of study: Annibali G, Musumeci G

\section{Availability of data and materials}

Not applicable.

\section{Financial support and sponsorship}

None.

\section{Conflicts of interest}

All authors declared that there are no conflicts of interest.

\section{Ethical approval and consent to participate}

Not applicable.

\section{Consent for publication}

Not applicable.

\section{Copyright}

(c) The Author(s) 2022.

\section{REFERENCES}

1. Vemulapalli S, Carroll JD, Mack MJ, et al. Procedural volume and outcomes for transcatheter aortic-valve replacement. $N$ Engl $J$ Med 2019;380:2541-50. DOI PubMed

2. Dvir D, Webb JG, Bleiziffer S, et al; Valve-in-Valve International Data Registry Investigators. Transcatheter aortic valve implantation in failed bioprosthetic surgical valves. JAMA 2014;312:162-70. DOI PubMed

3. Carroll JD, Mack MJ, Vemulapalli S, et al. STS-ACC TVT registry of transcatheter aortic valve replacement. J Am Coll Cardiol 2020;76:2492-516. DOI PubMed

4. Webb JG, Murdoch DJ, Alu MC, et al. 3-year outcomes after valve-in-valve transcatheter aortic valve replacement for degenerated bioprostheses: the PARTNER 2 registry. J Am Coll Cardiol 2019;73:2647-55. DOI PubMed

5. Capodanno D, Petronio AS, Prendergast B, et al. Standardized definitions of structural deterioration and valve failure in assessing 
long-term durability of transcatheter and surgical aortic bioprosthetic valves: a consensus statement from the European Association of Percutaneous Cardiovascular Interventions (EAPCI) endorsed by the European Society of Cardiology (ESC) and the European Association for Cardio-Thoracic Surgery (EACTS). Eur J Cardiothorac Surg 2017;38:3382-90. DOI

6. Généreux P, Piazza N, Alu MC, et al; VARC-3 Writing Committee. Valve academic research consortium 3: updated endpoint definitions for aortic valve clinical research. J Am Coll Cardiol 2021;77:2717-46. DOI PubMed

7. Otto CM, Nishimura RA, Bonow RO, et al; Writing Committee Members. 2020 ACC/AHA Guideline for the management of patients with valvular heart disease: executive summary: a report of the American College of Cardiology/American Heart Association Joint Committee on Clinical Practice Guidelines. J Am Coll Cardiol 2021;77:450-500. DOI PubMed

8. Vahanian A, Beyersdorf F, Praz F, et al. 2021 ESC/EACTS Guidelines for the management of valvular heart disease. EuroIntervention 2022;17:e1126-96. DOI PubMed

9. Sá MPBO, Van den Eynde J, Simonato M, et al. Valve-in-valve transcatheter aortic valve replacement versus redo surgical aortic valve replacement: an updated meta-analysis. JACC Cardiovasc Interv 2021;14:211-20. DOI PubMed

10. Thandra A, Abusnina W, Jhand A, et al. Valve-in-valve transcatheter aortic valve replacement versus redo surgical valve replacement for degenerated bioprosthetic aortic valve: an updated meta-analysis comparing midterm outcomes. Catheter Cardiovasc Interv 2021;97:1481-8. DOI PubMed

11. Saleem S, Ullah W, Syed MA, et al. Meta-analysis comparing valve-in-valve TAVR and redo-SAVR in patients with degenerated bioprosthetic aortic valve. Catheter Cardiovasc Interv 2021;98:940-7. DOI PubMed

12. Tarantini G, Dvir D, Tang GHL. Transcatheter aortic valve implantation in degenerated surgical aortic valves. EuroIntervention 2021;17:709-19. DOI PubMed

13. Edelman JJ, Khan JM, Rogers T, et al. Valve-in-valve TAVR: state-of-the-art review. Innovations (Phila) 2019;14:299-310. DOI PubMed

14. Simonato M, Dvir D. Transcatheter aortic valve replacement in failed surgical valves. Heart 2019;105:s38-43. DOI PubMed

15. Duncan A, Moat N, Simonato M, et al. Outcomes following transcatheter aortic valve replacement for degenerative stentless versus stented bioprostheses. JACC Cardiovasc Interv 2019;12:1256-63. DOI PubMed

16. Ribeiro HB, Rodés-Cabau J, Blanke P, et al. Incidence, predictors, and clinical outcomes of coronary obstruction following transcatheter aortic valve replacement for degenerative bioprosthetic surgical valves: insights from the VIVID registry. Eur Heart $J$ 2018;39:687-95. DOI PubMed

17. Alnasser S, Cheema AN, Simonato M, et al; Valve-in-Valve International Data Registry Investigators. Matched comparison of selfexpanding transcatheter heart valves for the treatment of failed aortic surgical bioprosthesis: insights from the valve-in-valve international data registry (VIVID). Circ Cardiovasc Interv 2017;10:e004392. DOI PubMed

18. Seiffert M, Treede H, Schofer J, et al. Matched comparison of next- and early-generation balloon-expandable transcatheter heart valve implantations in failed surgical aortic bioprostheses. EuroIntervention 2018;14:e397-404. DOI PubMed

19. Francone M, Budde RPJ, Bremerich J, et al. CT and MR imaging prior to transcatheter aortic valve implantation: standardisation of scanning protocols, measurements and reporting-a consensus document by the European Society of Cardiovascular Radiology (ESCR). Eur Radiol 2020;30:2627-50. DOI PubMed PMC

20. Bapat V. Valve-in-valve apps: why and how they were developed and how to use them. EuroIntervention 2014;10 Suppl U:U44-51. DOI PubMed

21. Jabbour RJ, Tanaka A, Finkelstein A, et al. Delayed coronary obstruction after transcatheter aortic valve replacement. $J$ Am Coll Cardiol 2018;71:1513-24. DOI PubMed

22. Dvir D. Treatment of small surgical valves: clinical considerations for achieving optimal results in valve-in-valve procedures. JACC Cardiovasc Interv 2015;8:2034-6. DOI PubMed

23. Rodés-Cabau J, Pibarot P, Suri RM, et al. Impact of aortic annulus size on valve hemodynamics and clinical outcomes after transcatheter and surgical aortic valve replacement: insights from the PARTNER Trial. Circ Cardiovasc Interv 2014;7:701-11. DOI PubMed

24. Ochiai T, Oakley L, Sekhon N, et al. Risk of coronary obstruction due to sinus sequestration in redo transcatheter aortic valve replacement. JACC Cardiovasc Interv 2020;13:2617-27. DOI PubMed

25. Blanke P, Soon J, Dvir D, et al. Computed tomography assessment for transcatheter aortic valve in valve implantation: the vancouver approach to predict anatomical risk for coronary obstruction and other considerations. J Cardiovasc Comput Tomogr 2016;10:491-9. DOI PubMed

26. Dvir D, Leipsic J, Blanke P, et al. Coronary obstruction in transcatheter aortic valve-in-valve implantation: preprocedural evaluation, device selection, protection, and treatment. Circ Cardiovasc Interv 2015;8:e02079. DOI PubMed

27. Mercanti F, Rosseel L, Neylon A, et al. Chimney stenting for coronary occlusion during TAVR: insights from the chimney registry. JACC Cardiovasc Interv 2020;13:751-61. DOI PubMed

28. Romano V, Buzzatti N, Latib A, Colombo A, Montorfano M. Chimney technique for coronary obstruction after aortic valve in valve: pros and cons. Eur Heart J Cardiovasc Imaging 2018;19:1194. DOI PubMed

29. Khan JM, Dvir D, Greenbaum AB, et al. Transcatheter laceration of aortic leaflets to prevent coronary obstruction during transcatheter aortic valve replacement: concept to first-in-human. JACC Cardiovasc Interv 2018;11:677-89. DOI PubMed PMC

30. Khan JM, Greenbaum AB, Babaliaros VC, et al. The BASILICA trial: prospective multicenter investigation of intentional leaflet laceration to prevent TAVR coronary obstruction. JACC Cardiovasc Interv 2019;12:1240-52. DOI PubMed PMC

31. De Backer O, Søndergaard L. Is BASILICA the standard for preventing coronary obstruction in high-risk transcatheter aortic valve replacement? JACC Cardiovasc Interv 2021;14:949-51. DOI PubMed 
32. Khan JM, Babaliaros VC, Greenbaum AB, et al. Preventing coronary obstruction during transcatheter aortic valve replacement: results from the multicenter international BASILICA registry. JACC Cardiovasc Interv 2021;14:941-8. DOI PubMed PMC

33. Tarantini G, Fabris T, Nai Fovino L. TAVR-in-TAVR and coronary access: importance of preprocedural planning. EuroIntervention 2020;16:e129-32. DOI PubMed

34. Nai Fovino L, Scotti A, Massussi M, et al. Coronary angiography after transcatheter aortic valve replacement (TAVR) to evaluate the risk of coronary access impairment after TAVR-in-TAVR. J Am Heart Assoc 2020;9:e016446. DOI PubMed PMC

35. Tang GHL, Zaid S, Gupta E, et al. Feasibility of repeat tavr after SAPIEN 3 TAVR: a novel classification scheme and pilot angiographic study. JACC Cardiovasc Interv 2019;12:1290-2. DOI PubMed

36. Akodad M, Sellers S, Gulsin GS, et al. Leaflet and neoskirt height in transcatheter heart valves: implications for repeat procedures and coronary access. JACC Cardiovasc Interv 2021;14:2298-300. DOI PubMed

37. Tang GHL, Komatsu I, Tzemach L, et al. Risk of coronary obstruction and the need to perform BASILICA: the VIVID classification. EuroIntervention 2020;16:e757-9. DOI PubMed

38. Tarantini G, Fabris T, Cardaioli F, Nai Fovino L. Coronary access after transcatheter aortic valve replacement in patients with bicuspid aortic valve: lights and shades. JACC Cardiovasc Interv 2019;12:1190-1. DOI PubMed

39. De Backer O, Landes U, Fuchs A, et al. Coronary access after TAVR-in-TAVR as evaluated by multidetector computed tomography. JACC Cardiovasc Interv 2020;13:2528-38. DOI PubMed

40. Bilkhu R, Jahangiri M, Otto CM. Patient-prosthesis mismatch following aortic valve replacement. Heart 2019;105:s28-33. DOI PubMed

41. Wendt D, Thielmann M, Plicht B, et al. The new St Jude Trifecta versus Carpentier-Edwards Perimount Magna and Magna Ease aortic bioprosthesis: is there a hemodynamic superiority? J Thorac Cardiovasc Surg 2014;147:1553-60. DOI PubMed

42. Herrmann HC, Daneshvar SA, Fonarow GC, et al. Prosthesis-patient mismatch in patients undergoing transcatheter aortic valve replacement: from the STS/ACC TVT registry. J Am Coll Cardiol 2018;72:2701-11. DOI PubMed

43. Vemulapalli S, Holmes DR Jr, Dai D, et al. Valve hemodynamic deterioration and cardiovascular outcomes in TAVR: a report from the STS/ACC TVT Registry. Am Heart J 2018;195:1-13. DOI PubMed

44. Flameng W, Herregods MC, Vercalsteren M, Herijgers P, Bogaerts K, Meuris B. Prosthesis-patient mismatch predicts structural valve degeneration in bioprosthetic heart valves. Circulation 2010;121:2123-9. DOI PubMed

45. Jie Yao R, Simonato M, Dvir D; Department of Cardiology, St Paul's Hospital, Vancouver, Canada, Department of Cardiology, St Paul's Hospital, Vancouver, Canada, Department of Cardiology, St Paul's Hospital, Vancouver, Canada. Optimising the haemodynamics of aortic valve-in-valve procedures. Interv Cardiol 2017;12:40. DOI

46. Pibarot P, Simonato M, Barbanti M, et al. Impact of pre-existing prosthesis-patient mismatch on survival following aortic valve-invalve procedures. JACC Cardiovasc Interv 2018;11:133-41. DOI PubMed

47. Jilaihawi H, Chin D, Spyt T, et al. Prosthesis-patient mismatch after transcatheter aortic valve implantation with the MedtronicCorevalve bioprosthesis. Eur Heart J 2010;31:857-64. DOI PubMed

48. Simonato M, Webb J, Bleiziffer S, et al. Current generation balloon-expandable transcatheter valve positioning strategies during aortic valve-in-valve procedures and clinical outcomes. JACC Cardiovasc Interv 2019;12:1606-17. DOI PubMed

49. Simonato M, Azadani AN, Webb J, et al. In vitro evaluation of implantation depth in valve-in-valve using different transcatheter heart valves. EuroIntervention 2016;12:909-17. DOI PubMed

50. Azadani AN, Reardon M, Simonato M, et al. Effect of transcatheter aortic valve size and position on valve-in-valve hemodynamics: an in vitro study. J Thorac Cardiovasc Surg 2017;153:1303-15.e1. DOI PubMed

51. Zenses AS, Evin MA, Stanová V, et al. Effect of size and position of self-expanding transcatheter valve on haemodynamics following valve-in-valve procedure in small surgical bioprostheses: an in vitro study. EuroIntervention 2018;14:e282-9. DOI PubMed

52. Dvir D, Khan J, Kornowski R, et al. Novel strategies in aortic valve-in-valve therapy including bioprosthetic valve fracture and BASILICA. EuroIntervention 2018;14:AB74-82. DOI PubMed

53. Grubitzsch H, Galloni M, Falk V. Wrinkles, folds and calcifications: reduced durability after transcatheter aortic valve-in-valve replacement. J Thorac Cardiovasc Surg 2017;153:266-8. DOI PubMed

54. Allen KB, Chhatriwalla AK, Cohen DJ, et al. Bioprosthetic valve fracture to facilitate transcatheter valve-in-valve implantation. Ann Thorac Surg 2017;104:1501-8. DOI PubMed

55. Saxon JT, Allen KB, Cohen DJ, Chhatriwalla AK. Bioprosthetic valve fracture during valve-in-valve TAVR: bench to bedside. Interv Cardiol 2018;13:20-6. DOI PubMed PMC

56. Chhatriwalla AK, Allen KB, Saxon JT, et al. Bioprosthetic valve fracture improves the hemodynamic results of valve-in-valve transcatheter aortic valve replacement. Circ Cardiovasc Interv 2017;10:e005216. DOI PubMed

57. Ziccardi MR, Groves EM. Bioprosthetic valve fracture for valve-in-valve transcatheter aortic valve replacement: rationale, patient selection, technique, and outcomes. Interv Cardiol Clin 2019;8:373-82. DOI PubMed

58. Nielsen-Kudsk JE, Andersen A, Therkelsen CJ, et al. High-pressure balloon fracturing of small dysfunctional Mitroflow bioprostheses facilitates transcatheter aortic valve-in-valve implantation. EuroIntervention 2017;13:e1020-5. DOI PubMed

59. Patel JS, Krishnaswamy A, White J, et al. Optimizing hemodynamics of transcatheter aortic valve-in-valve implantation in 19-mm surgical aortic prostheses. Catheter Cardiovasc Interv 2018;92:550-4. DOI PubMed

60. Tamagnini G, Bourguignon T, Rega F, et al. Device profile of the Inspiris Resilia valve for aortic valve replacement: overview of its safety and efficacy. Expert Rev Med Devices 2021;18:239-44. DOI PubMed

61. Okamoto Y, Yamamoto K, Sugimoto T, Yoshii S. Early and late outcomes of AVR with aortic annular enlargement in octogenarian. Gen Thorac Cardiovasc Surg 2015;63:453-8. DOI PubMed 
62. Mack MJ, Leon MB, Thourani VH, et al; PARTNER 3 Investigators. Transcatheter aortic-valve replacement with a balloonexpandable valve in low-risk patients. $N$ Engl J Med 2019;380:1695-705. DOI PubMed

63. Popma JJ, Deeb GM, Yakubov SJ, et al; Evolut Low Risk Trial Investigators. Transcatheter aortic-valve replacement with a selfexpanding valve in low-risk patients. N Engl J Med 2019;380:1706-15. DOI PubMed

64. Tarantini G, Nai Fovino L. Lifetime strategy of patients with aortic stenosis: the first cut is the deepest. JACC Cardiovasc Interv 2021:14:1727-30. DOI PubMed

65. Tarantini G, Nai Fovino L, Le Prince P, et al. Coronary access and percutaneous coronary intervention up to 3 years after transcatheter aortic valve implantation with a balloon-expandable valve. Circ Cardiovasc Interv 2020;13:e008972. DOI PubMed PMC

66. Bapat VN, Zaid S, Fukuhara S, et al; EXPLANT-TAVR Investigators. Surgical explantation after TAVR failure: Mid-term outcomes from the EXPLANT-TAVR international registry. JACC Cardiovasc Interv 2021;14:1978-91. DOI PubMed

67. Fukuhara S, Brescia AA, Shiomi S, et al. Surgical explantation of transcatheter aortic bioprostheses: results and clinical implications. $J$ Thorac Cardiovasc Surg 2021;162:539-47.e1. DOI PubMed PMC

68. Percy ED, Harloff MT, Hirji S, et al. Nationally representative repeat transcatheter aortic valve replacement outcomes: report from the centers for medicare and medicaid services. JACC Cardiovasc Interv 2021;14:1717-26. DOI PubMed

69. Hirji SA, Percy ED, McGurk S, et al. Incidence, characteristics, predictors, and outcomes of surgical explantation after transcatheter aortic valve replacement. J Am Coll Cardiol 2020;76:1848-59. DOI PubMed

70. Landes U, Webb JG, De Backer O, et al. Repeat transcatheter aortic valve replacement for transcatheter prosthesis dysfunction. $J \mathrm{Am}$ Coll Cardiol 2020;75:1882-93. DOI PubMed

71. Attizzani GF, Ohno Y, Latib A, et al. Acute and long-term (2-years) clinical outcomes of the CoreValve $31 \mathrm{~mm}$ in large aortic annuli: a multicenter study. Int J Cardiol 2017;227:543-9. DOI PubMed

72. Barbanti M, Webb JG, Tamburino C, et al. Outcomes of redo transcatheter aortic valve replacement for the treatment of postprocedural and late occurrence of paravalvular regurgitation and transcatheter valve failure. Circ Cardiovasc Interv 2016;9:e003930. DOI PubMed

73. Barbanti M, Costa G, Picci A, et al. Coronary cannulation after transcatheter aortic valve replacement: the RE-ACCESS study. JACC Cardiovasc Interv 2020;13:2542-55. DOI PubMed

74. Bleiziffer S, Simonato M, Webb JG, et al. Long-term outcomes after transcatheter aortic valve implantation in failed bioprosthetic valves. Eur Heart J 2020;41:2731-42. DOI PubMed

75. Chakravarty T, Søndergaard L, Friedman J, et al. Subclinical leaflet thrombosis in surgical and transcatheter bioprosthetic aortic valves: an observational study. Lancet 2017;389:2383-92. DOI PubMed

76. Blanke P, Leipsic JA, Popma JJ, et al; Evolut Low Risk LTI Substudy Investigators. Bioprosthetic aortic valve leaflet thickening in the evolut low risk sub-study. J Am Coll Cardiol 2020;75:2430-42. DOI PubMed

77. De Backer O, Dangas GD, Jilaihawi H, et al; GALILEO-4D Investigators. Reduced leaflet motion after transcatheter aortic-valve replacement. N Engl J Med 2020;382:130-9. DOI PubMed

78. Makkar RR, Fontana G, Jilaihawi H, et al. Possible subclinical leaflet thrombosis in bioprosthetic aortic valves. $N$ Engl J Med 2015;373:2015-24. DOI PubMed

79. Dangas GD, Tijssen JGP, Wöhrle J, et al; GALILEO Investigators. A controlled trial of rivaroxaban after transcatheter aortic-valve replacement. N Engl J Med 2020;382:120-9. DOI PubMed

80. Nijenhuis VJ, Brouwer J, Delewi R, et al. Anticoagulation with or without Clopidogrel after transcatheter aortic-valve implantation. $N$ Engl J Med 2020;382:1696-707. DOI PubMed

81. Brouwer J, Nijenhuis VJ, Delewi R, et al. Aspirin with or without Clopidogrel after transcatheter aortic-valve implantation. $N$ Engl $J$ Med 2020;383:1447-57. DOI PubMed

82. Makkar RR, Blanke P, Leipsic J, et al. Subclinical leaflet thrombosis in transcatheter and surgical bioprosthetic valves: PARTNER 3 cardiac computed tomography substudy. J Am Coll Cardiol 2020;75:3003-15. DOI PubMed

83. Abdel-Wahab M, Simonato M, Latib A, et al. Clinical valve thrombosis after transcatheter aortic valve-in-valve implantation. Circ Cardiovasc Interv 2018;11:e06730. DOI PubMed

84. Ten Berg J, Sibbing D, Rocca B, et al. Management of antithrombotic therapy in patients undergoing transcatheter aortic valve implantation: a consensus document of the ESC Working Group on Thrombosis and the European Association of Percutaneous Cardiovascular Interventions (EAPCI), in collaboration with the ESC Council on Valvular Heart Disease. Eur Heart J 2021;42:2265-9. DOI PubMed

85. Jose J, Sulimov DS, El-Mawardy M, et al. Clinical bioprosthetic heart valve thrombosis after transcatheter aortic valve replacement: incidence, characteristics, and treatment outcomes. JACC Cardiovasc Interv 2017;10:686-97. DOI PubMed

86. Vahidkhah K, Javani S, Abbasi M, et al. Blood stasis on transcatheter valve leaflets and implications for valve-in-valve leaflet thrombosis. Ann Thorac Surg 2017;104:751-9. DOI PubMed

87. Brown ML, Park SJ, Sundt TM, Schaff HV. Early thrombosis risk in patients with biologic valves in the aortic position. $J$ Thorac Cardiovasc Surg 2012;144:108-11. DOI PubMed

88. Eggebrecht H, Schmermund A, Voigtländer T, Kahlert P, Erbel R, Mehta RH. Risk of stroke after transcatheter aortic valve implantation (TAVI): a meta-analysis of 10,037 published patients. EuroIntervention 2012;8:129-38. DOI PubMed

89. Eitan A, Brinkmann C, Haselbach T, Witt J, Schofer J. Does valve in valve TAVR carry a higher risk for thromboembolic events compared to native valve TAVR? Catheter Cardiovasc Interv 2020;95:1017-21. DOI PubMed

90. Macherey S, Meertens M, Mauri V, et al. Meta-analysis of stroke and mortality rates in patients undergoing valve-in-valve transcatheter aortic valve replacement. $J$ Am Heart Assoc 2021;10:e019512. DOI PubMed PMC 
91. Lansky AJ, Schofer J, Tchetche D, et al. A prospective randomized evaluation of the TriGuard ${ }^{\mathrm{TM}} \mathrm{HDH}$ embolic DEFLECTion device during transcatheter aortic valve implantation: results from the DEFLECT III trial. Eur Heart J 2015;36:2070-8. DOI PubMed

92. Kapadia SR, Kodali S, Makkar R, et al; SENTINEL Trial Investigators. Protection against cerebral embolism during transcatheter aortic valve replacement. J Am Coll Cardiol 2017;69:367-77. DOI PubMed

93. Shimamura J, Kuno T, Malik A, et al. Safety and efficacy of cerebral embolic protection devices in patients undergoing transcatheter aortic valve replacement: a meta-analysis of in-hospital outcomes. Cardiovasc Interv Ther 2021. DOI PubMed 